Article

\title{
'Focusing and Unfocusing'-Cognitive, Evaluative, and Emotional Dynamics in the Relationship with Human Embryos among ART Beneficiaries
}

\author{
Luís Gouveia *(D) and Catarina Delaunay (D)
}

check for

updates

Citation: Gouveia, L.; Delaunay, C.

'Focusing and Unfocusing'-

Cognitive, Evaluative, and Emotional

Dynamics in the Relationship with

Human Embryos among ART

Beneficiaries. Societies 2022, 12, 7 .

https://doi.org/10.3390/soc12010007

Academic Editors: Violeta Alarcão,

Sónia Cardoso Pintassilgo and

Gregor Wolbring

Received: 30 September 2021

Accepted: 30 December 2021

Published: 5 January 2022

Publisher's Note: MDPI stays neutral with regard to jurisdictional claims in published maps and institutional affiliations.

Copyright: (C) 2022 by the authors. Licensee MDPI, Basel, Switzerland. This article is an open access article distributed under the terms and conditions of the Creative Commons Attribution (CC BY) license (https:// creativecommons.org/licenses/by/ $4.0 /)$.
Interdisciplinary Centre of Social Sciences, Faculty of Social Sciences and Humanities, University Nova de Lisboa, 1070-312 Lisbon, Portugal; catarinadelaunay@fcsh.unl.pt

* Correspondence: lgouveia@fcsh.unl.pt

\begin{abstract}
This article uses data gathered from a study conducted in Portugal to examine the (plural and composite) conceptions that doctors, embryologists, and beneficiaries of Assisted Reproductive Technology (ART) have of the in vitro human embryo. Taking the sociology of engagements, developed by Thévenot, as its theoretical lens, the article draws on a total of 69 interviews with ART patients to analyse the plurality of fluid meanings produced about this biological entity, whose status is neither static nor universal. ART beneficiaries are likely to produce plural conceptions of the lab-generated embryo within the framework of different regimes of engagement, understood as cognitive and evaluative formats. These various pragmatic regimes, in turn, entail distinct emotional investments. When speaking about their relationship with embryos, beneficiaries therefore express plural emotional experiences, which are articulated using terms such as affection, love, detachment, loss, frustration, hope, mourning, and anguish. Using the theoretical framework of the sociology of engagements, we propose an approach that enables us to produce a detailed record of the connections between the cognitive, evaluative, and emotional dimensions in beneficiaries' relationship with—and decision-making processes about-the embryos, accounting for the plasticity of emotional states linked to the (re)configuration of attributed meanings.
\end{abstract}

Keywords: in vitro human embryo; ART beneficiaries; regimes of engagement; moral evaluations; emotional states

\section{Introduction}

The birth of the first baby using in vitro fertilization, in the late 1970s, made the creation of humans through assisted reproductive technologies (ART) - in which the embryo is conceived outside the mother's womb [1] - a reality. This technology's development, part of the technoscientification of contemporary medicine [2], is one of the most important innovations of recent decades, and it has provoked controversies over the ontological status of the human embryo. These have led to ethical debates on the use of embryo material for purposes other than those strictly associated with medically assisted reproduction and, specifically, for scientific investigation $[3,4]$.

Reflecting the impact of this technology, a large amount of academic research has been produced. In the social and human sciences, this research has focused particularly on the experience of couples and women who resort to this medical specialty. For example, research has been conducted that examines the embryo as the object of different representations that vary in accordance with the different stages of the fertility treatment. The embryo is neither a static nor a universal biological entity, but it has fluid meanings produced about and statuses conferred on it [5-7]. The human embryo can thus be viewed as child, offspring, potential person, life, viable reproductive product, cluster of cells, lab artefact, or something expendable [4,6]. It can, therefore, be conceptualized in a plurality of ways, 
both by different ART beneficiaries and by one and the same beneficiary at different points in their therapeutic and personal trajectory $[5,8]$.

The embryo grown in a lab is thus the object of ontological manipulations $[7,9,10]$ and of construction and classification using different categories (which are associated with taxonomic structures). These processes of construction and classification are shaped by the embryo's temporal and spatial location, and by what its destiny will be-namely insertion in a parental project, cryopreservation, donation to other couples, use for scientific research, or destruction [11].

Indeed, in vitro human embryos do not differ from spontaneously generated embryos in their biological composition. It is their location outside the uterus at this stage of their existence that makes them susceptible to manipulation, opening up ethical, legal, and moral questions and uncertainties [12]. If medical doctors/embryologists and jurists frame the status of human embryos in medical-scientific and/or legal categoriesproviding a normative framework for their perspectives on, and interventions related to, the embryo [13] - potential parents are likely to display more plasticity in their ontological relationships with this entity. Their actions and decisions are framed by a plurality of moral principles-a plurality favoured by a cultural context (that of Western societies) in which public discourse around the embryo's status has, so far, not become settled [13,14].

Within this complex web of ambiguous meanings that couples involved in medically assisted reproduction produce, the moral status of the embryo emerges as a central element in these couples' decisions. Academic research into the relationship between these conceptualizations and decision-making processes has focused, particularly, on the context of deliberation about embryos that become surplus following an IVF/ICSI treatment [11,15-17]. However, this production of meanings also occurs at earlier stages of the therapeutic process, starting from the moment of the embryos' creation in the laboratory to their transfer to the uterus. It is this ontological plasticity across the beneficiaries' entire clinical trajectory that this article seeks to address.

Other studies-particularly those in psychology—also focus on ART beneficiaries' emotional experiences. Their ontological manipulations are found to translate into different ways of constructing emotional connections or disconnections with the embryo, as well as emotional states associated with the diagnosis of infertility and engagement in the therapeutic trajectory. In the course of the therapeutic trajectory, a plethora of emotional experiences is, therefore, likely to emerge. These are associated with beneficiaries' experience of infertility as a crisis of the parental project $[18,19]$, but they are also linked to the plurality of meanings constructed around the embryo $[20,21]$. These studies detail oscillations in emotional states throughout the therapeutic trajectory as levels of stress, anxiety, anguish, and depression fluctuate relative to beneficiaries' proximity to the infertility diagnosis and to moments of failure to achieve pregnancy [22-24]. Meanwhile, other studies focus on couples' varying emotional connections with the embryo and how this affects their decisions (as is the case with the choice to destroy or donate spare cryopreserved embryos) due to conceptualizations that transcend strictly instrumental perspectives $[17,20]$.

Again, these studies focus, firstly, on the emotional bonds built around the embryo in the context of the parental project's closure, which relegates the embryo to the status of surplus and requires the parents to decide whether to donate it (to science or other couples) or destroy it. Secondly, the emotional experiences these studies map centre mainly on emotional states associated with the (non-)achievement of pregnancy-falling into categories such as depression, anxiety, or frustration-and coping strategies directed specifically at moments of success or failure during treatments $[18,22,24]$.

This article, by contrast, seeks to understand beneficiaries' emotional experience more broadly. It specifically aims to grasp those oscillations in emotional experience that are not necessarily linked to an infertility diagnosis or to failures in obtaining pregnancy-i.e., to moments of crisis in the parental project. Our focus will instead be on emotional fluctuations and nuances associated with the existing in vitro embryo-fluctuations and nuances that 
vary according to the different contingencies in patients' therapeutic trajectories, not just their processes of (dis)attachment when deciding on surplus embryos.

Drawing on data gathered by a research project that addresses this ontological plurality of the human embryo, this article introduces a new perspective on this multiplicity of conceptualizations of the human embryo and its associated emotional experiences. Employing a theoretical framework, commonly named pragmatic sociology [25-27], we intend to develop a more detailed understanding of how the oscillations in meanings, constructed around the embryo, relate to the different emotions experienced in the course of the therapeutic trajectory (and about the relationship with the embryo in particular)-emotions that change along with these reconfigurations of the moral status conferred on the embryo.

By linking together cognitive, evaluative, and emotional dynamics through this theoretical framework, we intend to highlight the role of emotions in triggering embryos' reclassification, as well as in closing these moments in which the status attributed to this entity is reconfigured. In these processes, the cognitive-evaluative dimension (i.e., categorization and the associated moral judgment) and the emotional dimension of the relationship with the in vitro human embryo affect one another.

Lastly, our analysis aims to provide knowledge about the cognitive-evaluative and emotional dynamics of the beneficiaries who use medically-assisted reproduction technologies, particularly in their relationship with the embryo. The data we have collected support reflection on, and intervention to improve, the quality of information and psychological support provided to beneficiaries in ART centres. We hope this will bring about better management, counselling, and support throughout decision-making processes, involving lab-grown embryos, which involve a heavy emotional load [8,17].

\section{Materials and Methods}

This article is based on data gathered from an ongoing investigation, in Portugal, into the plurality of meanings produced about the human embryo. The project is named "ETHICHO_Ethico-ontological choreographies: Forms of objectification and evaluation of the human embryo in vitro in the context of Assisted Reproductive Technologies and Scientific Research". It seeks to analyse the plural and composite conceptions that doctors, biologists, and beneficiaries construct around the in vitro human embryo within the context of ART.

Indeed, the embryo is likely to be the object of different representations, which, in turn, rest-according to the theoretical framework we have chosen for this project-on different regimes of engagement $[25,26]$, understood as different cognitive and evaluative formats deployed by actors to comprehend their environment [28] —and in this specific case, different formats deployed in order to comprehend the embryo.

To put it as succinctly as possible, this theoretical framework contains a tripartite conceptualization of different regimes of engagement in action, understood as different formats for apprehending a given environment both cognitively (categorization and apprehension of relevant elements in a situation) and evaluatively (in the sense that this categorization and apprehension aims at a given moral good that serves as support to the coordination) $[25,26]$. The different regimes of engagement in action are located at different positions along an analytical axis that ranges from the general to the particular-i.e., from collective conventions of the public sphere to local and familiar references for action.

In the regime of public justification, action is supported by orders of collective conventions. These collective conventions constitute cognitive and moral frameworks that support the classification of (human or non-human) beings into equivalence classes. Beings within a given equivalence class share a set of common characteristics that confer onto them a partially replaceable character [7]. Each of these conventional constructs-which are moral orders, or orders of worth-is used by actors to evaluate and organize the worth of the various beings in a situation. Each order of worth contains a specific moral perspective for the coordination of human action, in the sense that it concretely expresses a different conception of the common good. The orders of worth most relevant for our purposes 
in this article are: the domestic order of worth, in which tradition/generation/hierarchy constitutes the form of the common good through which the embryo is evaluated; the civic order of worth, in which it is the collective interest; the connectionist order of worth, in which it is the project/activity that links individuals; the industrial order of worth, in which it is efficacy.

Each order of worth identified refers to distinct conceptions of the common good, and consists of a publicly available grammar of making the common-a way of reaching commonality and differing through governing practices of criticism and justification [25,26]. The way in which each order of worth is translated into understandings of the embryos is shown throughout the text.

Concerning the remaining regimes, in the regime of engagement in a plan, reality is understood with reference to objectives that form the established plan, with the environment being functionally prepared, and the satisfaction of the accomplished action is the good aimed at. Lastly, in the regime of familiar engagement, action occurs within an area proximate to the actor, supported by this actor's familiarisation with their immediate environment. Comfort and ease are the good aimed at.

These differences, in relationship to the embryo, can thus be distinguished using the architecture of regimes of engagement conceptualized by Thévenot [26-28].

a. Regime of engagement in a plan: conception of the embryo as an abstract and replaceable resource, within a functional understanding-with the embryo understood as an instrument or a means, mobilized to attain an end (in this case, pregnancy).

b. Regime of public justification: conception of the embryo as falling into a moral class/equivalence category, thus sharing a set of characteristics (e.g., biological properties, insertion in a parental project, etc.) that is common to the beings within this category, through which they are evaluated and ranked, which makes the embryo partially replaceable. However, it is this understanding of the embryo in general terms - using equivalence principles that express senses of justice-that enables the embryo to rise in singularity as a criterion to confer total humanity [7]. This happens when the embryo is conceived of as a potential child or potential life, as part of an equivalence class associated with the connectionist conventional order, in the sense that it involves a parental/biological reproduction project of the progenitors; as genetic inheritance/offspring, in the sense that it is inserted into a network of kinship/lineage, in the conventional domestic order; as a cluster of cells/biological material, evaluated from the viewpoint of its genetic/morphological quality in the industrial conventional order; as a gift for scientific investigation or to other couples in the civic conventional order.

c. Regime of familiar engagement: a conception that singularises the embryo, treating it as a singular, irreplaceable entity - granter of total humanity [7]. This singularisation is very different from a functional or general understanding of the embryo (according to an equivalence principle), which, in this case, is conceived of as a child. This engagement format, in which an irreplaceable status is conferred on the embryo, becomes evident, for example, in the act of giving a name; where the embryo is lost, the non-attribution of this same name to another grown embryo attests to this particularization.

It is important to recognise that conceptions of the embryo are neither fixed nor watertight, but they can draw on different regimes of engagement-sometimes combining them-throughout beneficiaries' therapeutic trajectory. Moments of disquiet can occur [27] at any point in this trajectory, opening up the possibility of re-describing the embryo through a different regime of engagement (or combinations of different regimes).

Furthermore, beneficiaries' trajectories are also characterized by fluctuations in the emotional experiences that accompany the meanings produced about the embryos (and the procedures they undergo). In other words, different emotional ambiances/experiences are attached to different cognitive and evaluative operations. 
These different regimes of engagement combine cognition, evaluation, and emotion. On the one hand, they presuppose operations of investment in forms (i.e., material equipment, relational forms, etc.) that support the comprehension of the environment under a given cognitive and evaluative format [26]. On the other hand, each regime of engagement also involves emotional investments-emotional states/ambiences appropriate to the format, according to which the situation is apprehended. These ambiences give authenticity to an actor's engagement with a situation, reinforcing its apprehension according to the cognitive and evaluative format in question [29]. Emotions, therefore, support the interpretation of a situation, according to a given regime of engagement, and are a driving force behind individual and collective action [30].

Each order of worth involves the cognitive apprehension of a given situation in a way that balances its apprehension according to this order of worth and the sacrifice of other forms of apprehension linked to other orders, thus operating in a cognitive economy. But this cognitive apprehension also operates in an emotional economy, to the extent that there is an emotional experience associated with a state of worth and the sacrifice of emotional experiences associated with other orders of worth. Thus emotions participate in a cognitive economy and cognitive operations participate in an emotional economy [29]. This is the case, for example, with the emotional disattachment in the relationship with an embryo from a connectionist or domestic grammar-in view, for example, of enduring moments of failure in the therapeutic plan (such as the loss of embryos in vitro or in utero). This emotional disattachment from the embryo participates in a cognitive re-apprehension of it as, for example, biological material.

We can now describe the emotional dynamics that are associated with each regime of action, and which give each regime its specificity. The domestic grammar presupposes an emotional economy in which warmth is experienced in relationships with other beingsparticularly, in this case, the embryo-with these beings' disappearance (in this case, the loss/destruction of the embryo) experienced as an absence whose memory is prolonged in time [29]. The emotional ambiance can, likewise, be characterized by the use of categories such as affection, tenderness, or fondness towards the embryo, as well as sadness, pain, or abandonment in cases of loss or decisions to destroy or donate-categories that confer the typical emotional authenticity of relationships within a family group [29].

However, to identify the forms of engagement-and the corresponding moral and emotional categories-, we need to contextualize how terms are used by actors. This is the case, for instance, with interviewees' use of terms such as mourning or child, terms that might be associated with a familiar engagement with the embryos, but in whose context of use discourse analysis reveals situational dynamics that remain at the level of equivalences-and therefore distant from the genuine singularization that we would expect from familiar engagement.

In the connectionist grammar, emotions towards the embryo are based on its apprehension through categories such as hope and expectation, with the embryo understood as a being integrated into a parental project - therefore, as a potential child. In this grammar, conceiving a child is a project that is more robust and longer lasting than all others (personal, professional, etc.), and it is this robustness and durability that gives the parental project its authenticity [7]. It is the beneficiaries' desire for-and commitment to-the shared parental project that defines their relationship with, and emotional investment in, the embryo, and its loss is experienced as a disruption of this same promise, or expectation, that emotionally links the progenitors to it.

In contrast to the domestic grammar, the industrial grammar is characterized by sobriety. Relational warmth towards the embryo is replaced by the cold calculation of a relationship, mediated by scientific methods and procedures, with the embryo equated to a technical object. With action guided by the passion for efficacy [29], the loss of the embryo is emotionally experienced-in line with a principle of efficiency — as a failure in technical execution and a waste of its potential use as precious material (for reproduction or scientific investigation). The embryo is therefore evaluated according to its level of quality (which 
grants it industrial worth) and inserted into a larger mechanism, in equivalence with other technical devices.

In the civic grammar, the emotional experience is based on categories such as solidarity and gratitude, which express a connection between the beneficiary and the collective, in the sense that they are contributing to the general interest through impersonal mutuality [3]. This can occur through either scientific development, release, or detachment; the motivation is to help other beneficiaries, with the embryo viewed as a gift.

This grammar is discernible, therefore, in beneficiaries whose therapeutic trajectory leads to the embryo becoming surplus and thus, dissociated from the parental project that led to its creation in the first place. As the embryo is no longer understood through categories such as child or potential child by the beneficiaries, the civic grammar provides a normative framework for reconfiguring meaning around the embryo, enabling a continuous transition, without disruption, by partially preserving the meaning of the previous moral status attributed to it (thus providing ontological continuity). The new status requires an emotional investment in the embryo-albeit of a different nature- that does not fall into the technical distance associated with an understanding of the embryo as a set of cells (industrial grammar). This transfer to the civic grammar-a transfer between orders of worth [31] — provides beneficiaries with a less radical rupture, with the cognitive and moral understanding involved in (and emotional experience attached to) connectionist and domestic grammars, than would a direct transfer to the industrial grammar.

In the regime of engagement in a plan, the emotional ambiance is characterised by distance in relation to the embryo, expressed through categories such as frustration, disappointment, anxiety, anguish, and suffering, which are all emotional experiences related to the non-realization of the pursued goal—and in this case, to the uncertainty about whether the planned action will be accomplished, as well as the failure to achieve pregnancy, both of which are perceived as moments of crisis in the parental project [19]. Thus, these emotions are dissociated from the loss or destruction of the embryo itself and are directly linked to the couple's plan of having offspring.

Lastly, in the familiar engagement regime, categories such as love, protection, care, and bond become central, supporting forms of relation that are based on intimate gesturesgestures that are very different from actions based on the regime of equivalences [32] - and grounded in an understanding of the embryo as a singular being. Within this intense particularizing emotional investment (different from the still-replaceable character associated with the domestic grammar), mourning gains prominence as an emotional category in the case of embryo loss. The embryo's non-development is experienced as a loss that cannot be remedied through replacement by another entity; this is perceived as the loss of a child [7].

Now that we have presented our guiding theoretical-conceptual framework, this article will analyse how these cognitive-evaluative and emotional dynamics are connected to beneficiaries' relationships with the human embryo. More specifically, within this integrated trio of cognition, evaluation, and emotion, emotional experiences are a driving force, triggering (and closing down) reclassifications of the embryo [33]. It is the emotional experience that initiates the process of re-assessing the environment (in this particular case, the embryo) according to distinct cognitive and moral formats; it is the emotional experience that ultimately enables this moment of test to be closed down through the convergence between format of engagement and emotional ambiance [33].

Indeed, different points in the therapeutic trajectory tend to be accompanied by different emotional experiences, both individual (experienced by the beneficiary in line with a given regime of engagement) and collective, in the sense that emotions are common to the actors that coordinate action among themselves according to a given grammar [34]. However, it is in situations of disquiet-of questioning the formats of engagement used to understand the embryo-that these emotional experiences become more intense and tangible.

Our aim is to precisely illustrate this ontological and emotional plurality, with a particular focus on the stages of the therapeutic trajectory that are likely prompt beneficiaries to switch between distinct regimes of engagement and, consequently, reconfigure the moral 
status conferred on the embryo. This is the case in moments of loss (in utero or in vitro) and decision (e.g., donation, destruction, etc.).

The data presented results from interviews with beneficiaries of ART. A total of 69 interviews were conducted, by the same interviewer, between September 2019 and January 2021. The sample was composed of interviewees that had undergone second-line treatments - in vitro fertilization (IVF) and Intracytoplasmic Sperm Injection (ICSI) — which involve the production of embryos in a laboratory.

The interviews were conducted with respondents at different stages of their therapeutic trajectory-during treatment cycles, between cycles, or after already completing the process (with or without a pregnancy). Respondents' treatments took place within a largely similar timeframe: on average, those in the sample started their first treatment cycle in 2016 (standard deviation of 3.4), and their last treatment cycle occurred, on average, in 2020 (standard deviation of 2.9). Furthermore, a significant proportion of the respondents (approximately 20\%) were still in treatment at the time of the interview, with a cycle either in progress or due to begin.

Except for five who were born abroad, all interviewees were Portuguese nationals. Only three (female) respondents - all of whom were engaged in a homosexual parental project-went through IVF/ICSI treatment cycles, carried out in clinics located outside Portugal, in a period when the legal regulatory framework for ART in Portugal did not give this group access to treatments.

Concerning this issue, it is important to put into context and refer that, in Portugal, the first law regulating medically assisted procreation techniques, approved in 2006, restricted access to couples in a stable, heterosexual, marital union who had health problems (either infertility or risk of transmitting a genetic condition). However, a subsequent review of this legislation (Law 17/2016) gave all women access to ART, regardless of whether they had an infertility diagnosis, or of their marital status or sexual orientation. Access by male homosexual couples remains prohibited in the present legal framework.

The interviews were conducted both with individual users and with heterosexual and homosexual couples. The great majority of the interviewees were female (nearly 92\%) and engaged in heterosexual parental projects (approximately 95\%). Only four interviewees were engaged in homosexual parental projects.

The respondents were recruited online (from social networks or forums dealing with infertility) and from a patient association concerned with infertility-related diseases. Most had been through higher education $(81.1 \%)$, and a significant percentage had done some level of post-graduate study-either master's or doctoral degrees (35\%). Since this was a convenience sample-generated through appeals for participation using digital channelsa higher level of representativeness could not be attained either in terms of gender (i.e., male respondents) or in terms of non-heterosexual beneficiaries.

The interviewees were given pseudonyms to ensure anonymity. All interviews were recorded and transcribed verbatim, with analysis conducted using the qualitative analysis software MaxQDA (2018 version).

The interview guide encompassed several themes and sought to cover the different stages of the therapeutic trajectory both before and after completion of the treatments: the formation of the parental project; infertility diagnosis (if applicable) and decision to resort to specialized medical help; knowledge about ART; description of the therapeutic protocol and lived experienced; decision on surplus embryos (if applicable); general conceptions of, and forms of connection with, the created embryos (moral status attributed, moments of change in these understandings, beginning of the construction of an emotional bond, etc.).

With this article's specific goals in mind, we used categorical content analysis to identify the different ontological conceptions and the different emotional experiencesencompassing various emotions at various levels of intensity (emotional tonalities) - involved in the interviewees' relationship with the in vitro embryo, at different stages of the therapeutic trajectory. 
These different conceptualizations of, and emotional investments in, embryos must be analysed while taking into account the specific characteristics of our sampling process. This process did not seek to ensure a representative sample of participants in terms of sexual orientation, socioeconomic status, ethnic background, etc.; it was mostly restricted to a specific national context, as most respondents were Portuguese nationals and/or had undergone treatments in Portugal. Our analysis, therefore, focuses on capturing the grammatical diversity, and oscillation between grammars, among the study's participants without trying to generalize to other societal contexts or identify patterns according to sociodemographic variables.

\section{Results}

With the aim of examining these beneficiaries' changing relations with their embryoswhich involve oscillations between (and compositions of) the evaluations they make, and associated emotional experiences-we will analyse some interviews in which interviewees' discourse demonstrates, precisely, the multiplicity of regimes of action.

A first perspective is supplied by an interviewee whose therapeutic trajectory was made up of twelve treatment cycles. In total, 24 transferred embryos were generated (classified as viable), along with those that were discarded (the interviewee was unable to provide an exact figure). This long therapeutic trajectory thus serves as a window into the ontological choreographies [10] that beneficiaries can develop in their relationship with the embryos, combining different regimes of engagement-understood as cognitive and moral formats-along with plural and composite emotional ambiances.

Here, the interviewee's perspective is characterized by an understanding of the embryos using the category of children, revealing a transition (albeit complete) to a singularizing form of affective engagement with each one:

Valentina: "From the beginning they were my children ... They were mine, so to speak ... That's why it is so hard for me ... [ . . ] The news took such a toll ... They were my children who disappeared [ ... ]. I sometimes say to my husband 'We've lost twenty-four children' ... That was basically what I felt ... [ . . . ] If I have this conversation with my sisters-in-law, with my nieces and nephews, they won't understand this ... This is hard to explain to people who haven't gone through the process ... that to me they were my children too ... Like to them their children are those whom they felt growing in their bellies ..."

Demonstrating an openness to familiar engagement, her discourse shows how the intimate nature of a familiar representation of the embryo is difficult to communicate to those who do not share the same experience ("is hard to explain to people who haven't gone through the process") [27]. This construction of an emotional bond with the embryo in the absence of other ontological markers that signal the embryo's rise in singularity [7]such as the physical symptoms associated with pregnancy ("growing in their bellies")characterises the particularity of the experience of reproduction using ART.

Although this regime of engagement prevails in the interviewee's relationship with the lab-grown embryos across successive treatment cycles, her description (i.e., the position of the embryo in time and space) goes on to reveal that her representations of these embryos, and the corresponding emotional experiences, are more composite and oscillating:

Valentina: "But I also ... psychologically filtered that, and we focused only on the ones they said were ... So, if I were to worry ... to focus on everything, this would take an even greater toll ... [ ... ] And, in time, the feelings are complex and you create, we create filters, barriers so it won't ... it won't take as much of a toll, right? So, the focus was on the ones that were viable ... I tried not to think about it, no ... That is, because scientifically they weren't viable, they had genetic problems, that was how I thought ... That was how I had to think [ ... ]. But, there it is, our psychological filter, it's 'Don't think about that anymore, focus 
on the others' $\ldots$ This is very complex, $[\ldots]$ focusing and unfocusing $\ldots[\ldots]$

to safeguard me from suffering, because ... It's a very strong pain."

The interviewee uses the focusing-unfocusing pair to describe her oscillation between different cognitive-evaluative formats and their associated emotional experiences. The act of focusing is associated, particularly, with a break from instrumental and biological conceptions of the embryo, through a shift to a familiar form of engagement. This is characterized by a singularizing affect that brings the embryo closer to the status of a child, although it is still inserted in classes of equivalence-be it as a potential child (connectionist grammar) or as part of a kinship network (domestic grammar)-that make it partially replaceable. In turn, unfocusing is associated with an inversion in this process of humanizing the embryos and rising in singularity, as the embryos are relegated to the condition of biological material whose genetic quality renders them obsolete in light of the industrial grammar. Detachment therefore follows their classification as technical objects.

In this oscillation between formats of engaging with the embryo, the central role of scientific evaluative devices is highlighted. In particular, the scientific evaluation of the embryo's viability and quality - which, for the laboratory professionals, determines the embryo's industrial worth by identifying its efficacy as a resource-is what grants and reinforces the worth of the embryo as a potential child or progeny/offspring. The interviewee's speech therefore reveals a composition of grammars. Her understanding of the embryo as a child or potential child, and her gradual transition to familiar engagement, find support in objects from the industrial world [25], as she oscillates between emotional connection and disconnection to the in vitro embryo ("the focus was on the ones that were viable").

On the other hand, as the interviewee's language shows, these relational shifts-while still associated with an oscillation in moral status in accordance with the ontological marker in question (viability stemming from the embryo's scientific classification)—are also a way of preserving her engagement in the therapeutic trajectory. It is her desire to avoid "pain" - an emotional experience associated with her conception of the embryo as a child or potential child - that triggers a change in the status she attributes to the embryos evaluated as inviable. These start to be seen as biological material with "genetic problems", with the industrial grammar employed as a convention to support this evaluative judgment.

This dynamic of focusing-unfocusing illustrates the relationship between evaluation and emotion. The cognitive and evaluative operation participates in an emotional economy [29], aiming, in this case, to enable the beneficiary to endure the emotional impact associated with the loss of in vitro or in utero embryos and secure her continuation of the treatment process. It is this non-linearity, throughout the therapeutic trajectory, of the emotional experience (or emotional ambiance) - which is linked to the different cognitive and evaluative formats employed to apprehend the embryo- that is highlighted in the beneficiary's discourse ("the feelings are complex").

Another interviewee describes a similar oscillation in her emotional connection to the embryos-in this case, a weakening of this connection. Here, the accomplishment of the parental project, through a full-term twin pregnancy, leads her to change the status she attributes to the remaining cryopreserved embryos.

Ana: "And then the birth of the twins ... my memory also began ... And later I found out I was pregnant [new, spontaneous pregnancy] and so I forgot ... Then ... the memory was really very sporadic $[\ldots]$. There was that connection in the beginning, yes ... But later on, I have to be honest, no ... no ... The connection rested with the twins ... [ ... ] ... That's normal, isn't it? Because they're real ... ((laughs)), right?"

While, at first, the embryos were conceptualized as a potential child, the interviewee's connection with them is progressively attenuated after achieving the pregnancy with two transferred embryos ("the connection rested with the twins"). In light of the fulfilment of the promise associated with the transferred embryos, from the perspective of the parental 
project ("Because they're real"), the emotional connection with the remaining ones gradually dissipates over time ("the memory was really very sporadic"). If, in other interviews, the birth of a child leads to the meaning attributed to the remaining embryos being recomposed to reinforce their status as a potential child, in this case, the birth of twins (in addition to the spontaneous pregnancy with a third child) closes the parental project and gradually weakens the emotional connection with the embryos.

However, in this reconfiguration process, the status of the cryopreserved embryos does not return to that of instrument or cluster of cells. The emotional connection with the remaining embryos is reduced to a purely genetic connection, which undermines the embryos' status as a potential child. This is shown by the next excerpt from the same interview:

Ana: "I remember a situation, when I was already pregnant with [name of the son], who's the youngest ... I've just remembered ... The four of us were there, right? I was ... At that time they even wanted to walk ... And I don't know why ... [ ... ] One of them came to my belly to cuddle it ... And I remember saying: 'This is not your only sibling, there are other siblings, but the others-you'll never get to meet them ... '"'

The attribution of the status of sibling is rooted in an overlap between the genetic bond, in the framework of a domestic grammar, and the condition of potential child ("you'll never get to meet them"). Within this cognitive and moral operation, the original category of potential child gives way to the embryo being seen through the lens of a biological/genetic connection. This reclassification of the embryo in the sphere of equivalences-which stems from the closure of the parental project-is accompanied by an attenuation of the emotional experience of affective connection.

On this regard, it is important to stress that the interview data show that the ontological marker of obtaining a full-term pregnancy can bring about other reconfigurations in beneficiaries' conceptualizations of embryos. It can trigger a humanizing singularization of the remaining embryos; favour a transition from viewing them as biological material to considering them a potential child or child (e.g., in the sense that they are perceived as siblings of the already-born child); or prompt the embryos to be seen as a gift to other couples struggling to have a child. Due to space constraints, we can't use excerpts to illustrate this complex non-linear relationship between the completion of pregnancy and the reclassification of embryos that become surplus.

Another interviewee identifies a different ontological marker: he points to the embryo's transfer to the uterus as the moment that prompts a change in the format used to understand the embryo, which is accompanied by a shift in emotional experience:

Daniel: "Then, there's already ... The journey can be begun to ... to paternity ...

And then there's already ... There's already, always with this feeling of fear, about whether it'll succeed or not ... And even if it did generate a pregnancy, even then there would still be many, many possible risks of it not working, of having a miscarriage. But there, yes, there is already a small emotional connection, you think that the beginning of everything could be there."

The interviewee's emotional experience is summarized by the central category that he himself uses: "fear" about the pregnancy's realization or non-realization. This category sits within a connectionist grammar that inserts the embryo into the category of potential child-still distant, therefore, from an emotional experience associated with the prospect of losing a being perceived as a child. As the interviewee adds, there is a "small emotional connection", an openness to affective investment in the embryo. However, he still sees this embryo as part of a "journey [ ... ] to paternity", and therefore remains in an incipient phase of singularizing engagement.

Along with the transition between grammars used to understand the embryo, the testimony of another interviewee points to the revision-based on the connectionist grammarof the state of worth [25] conferred on the embryo (initially seen as a potential child) over 
the course of the therapeutic trajectory. Successive failures to obtain a pregnancy affect the moral status attributed to, and emotional experience of the relationship with, the embryos:

Bianca: "And everything leads us to believe them to be ... to be our children, isn't it? To us it was already a ... A living being, a human being ... A person. To us, it would already become a person, one day it would be a person, and it is very difficult for us to come to a point and say 'Hang on, this is still nothing.' At the end of the day, it still is nothing, right? It's ... . It's the beginning of something, but it may not be, and ... And this is ... At the time it was very frustrating because we had the embryos, I had everything for ... for it to go well ... [ . . ]. At the end, it was very difficult because we got to the point where we only wanted a positive pregnancy test, because that was what would make us certain that it was something, and not the embryo."

The experience of successive failures in transferring the embryos leads to a change in the status conferred on them. In this case, an initial understanding of the embryo as potential child ("one day it would be a person") is attenuated, as the in vitro embryo is relegated to a state of lesser worth under the same grammar ("the embryo is still nothing").

When we model how the formats of engagement change, in accordance with the different stages of the therapeutic trajectory, the pregnancy test becomes the central device that shifts the ontological status attributed to the embryo: a transition to the state of potential child is prompted by the test's confirmation of the probability of development ("certain that it was something"). Within the connectionist grammar, this stage raises the embryo supported by the pregnancy test to a state of worth higher than that attributed to the embryo not supported by this test [25]. This contrasts with the previous experience of the interviewee, in which the very existence of the embryo precociously granted that same status.

The same interviewee expands on this change in her evaluation of the embryo and her associated emotional experience:

Bianca: "And this process of accepting that embryos are just embryos is very difficult because we put all our hope in those four or five, and ... [... ] And the feeling that we always had about the embryos is that ... They were people, we spoke of them at home as if ... Those are our frozen boys there, right? [ . . ] For us the embryo was already the beginning ... right? It was already very important. And this is very difficult, to realize that we had to disconnect, and this process is very ... extremely hard."

Reiterating the embryo's initial status as a promise since the start of the therapeutic trajectory ("we put all our hope") - i.e., the first stage in a continuum that culminates in the end of pregnancy ("the embryo was already the beginning") — the interviewee's discourse reveals a change in the emotional economy associated with the therapeutic trajectory and, in particular, the relationship with the embryos. Failures lead to a reconfiguration in the format of engagement, which attenuates the status of the embryo as a potential child ("we had to disconnect").

There is, therefore, a revision of the in vitro embryos' state of worth, which brings these beings closer to their biological composition in the way they are evaluated. Consequently, the associated emotional experience is altered: a connection based on hope is weakened, as is the projection of the status of future child onto the embryo ("accepting that embryos are just embryos"). Again, the emotional experience of the loss of embryos ("extremely hard"), intensified by the initial conception of the embryos as potential children ("those are our frozen boys there"), leads to a reconfiguration of the moral status of those embryos generated afterwards.

Another interviewee reveals how the transition from the in vitro to the in utero condition does not constitute a transversal ontological marker. In her case, after the transfer of two embryos, one was lost. However, her discourse demonstrates how this transition of the 
embryo in space did not translate into a reconfiguration of its status, or of her emotional connection to it:

Olga: "So, the fact that there was an embryo ... To me it was already a victory ... Because ... I managed ... It wasn't two, okay, tough luck, it was one ... But ... It wasn't ... It wasn't as if it had been a miscarriage or as if I had lost it ... Because I think it was so little time ... that ... From the time I found out I was pregnant until I was certain it was only one, it was seven days ... [ . . ] When the doctor told me it was just one, that the other hadn't developed, I thought 'Okay, no ... no problem. I have one, which is more important' ... So I didn't see it as a loss, no ...."

The conception of the embryos as a promise or possibility, in this case, translates into an immediate detachment expressed in the interviewee's discourse ("It wasn't two, okay, tough luck [ ... ] no problem"). These embryos still have not been singularized, something evident in the interviewee's understanding of them as replaceable in light of the parental project's accomplishment ("I have one, which is more important"). In this case, it seems to be the length of the pregnancy that is preponderant in the construction of an emotional bond and in the gradual transition away from the regime of equivalences. The non-development of the embryo in utero is therefore not experienced as a "loss", in the sense of an emotional experience close to mourning, which is associated with the regime of proximity.

A similar experience can be identified in another interviewee. While the simultaneous transfer of two embryos raised the possibility of a twin pregnancy, the procedure resulted in the loss of one of the embryos and the consequent development of the pregnancy with a single embryo (carried to term). The interviewee's discourse shows how the moment of transfer does not trigger a rise in singularity [7] of the meaning attributed to the embryo.

Lila: "[ ... ] with lightness ... With naturalness, that is, it was what it had to be ... Deep down we were ready for the possibility of having two, that is, we knew that ... in the best or worst case, it would be two ... It was one, and it was excellent, that is ... any of the ... We wanted to have a child so much that any of the possibilities was good for us, and therefore we experienced it as natural ... [ ... ] we didn't feel it was a loss ... [ . . ] Of course, many times we thought 'What if it had been two?' ... Sometimes we think that, but it's not in the sense of it being a loss ..."

The realization of the full-term pregnancy through one of the transferred embryos constitutes the attainment of the parental project. In light of this, the loss of one of the embryos translates into an emotional experience described as "lightness" and "naturalness", reflecting the still replaceable character conferred on the embryos, which are understood as possibilities $[14,35]$ associated with a parental project. This remains distant from a humanizing form of engagement that would translate into an experience of loss associated with a singularized being ("we didn't feel it was a loss"). The retrospective outlook reinforces this conception. The scenario of twins is understood, precisely, as an unrealized possible outcome of the parental project, which distances the beneficiaries' emotional ambiance from that associated with familiar engagement ("it's not in the sense of it being a loss").

This interviewee's discourse, when discussing a previous failed treatment cycle, also reveals the particular importance they attribute to devices for biomedically evaluating the embryos in prompting changes in the meanings they ascribe to the embryo:

Lila: "In the first ICSI, it was that hope that ... that we would make it and that we'd have embryos ... But the embryos were not high-quality embryos, so, on the day for implanting them they warned us that the embryos were not perfect, that is, we were already a little hesitant ... But of course, when we found out they hadn't taken hold, of course, then we had a feeling of loss, of ... That hope 
we had created died there. The whole trajectory of the treatment creates a hope that we will have a child, and then, of course, it's lost, isn't it?"

When embryos are understood as a hope, the first indicators of their poor morphokinetic "quality" relegate these beings to a state of lesser worth because they reduce the possibility of generating a pregnancy ("they warned us that the embryos were not perfect"). This evaluation is accompanied by an associated inflection in the beneficiary's emotional experience, characterised by a regression in their nascent construction of a connection to the embryo understood as a potential child ("we were already a little hesitant").

The embryos' transfer to the uterus, and their subsequent failure to evolve, already corresponds to an intensified emotional experience, prompting the interviewee to use the category of "loss" to describe this occurrence. Her utterance highlights an experience still associated with the connectionist grammar, but with the embryo now associated with a different state of worth. This emotional state is associated with the failure of the parental project dependent on the non-evolved embryos, which are inserted into an equivalence class- "hope that we will have a child". It is this hope that was reinforced immediately after the transfer.

On this subject, it is worth to highlight the analytical potential of conceptualizing hope and expectation using the theoretical framework of regimes of engagement. Doing so allows us to avoid essentializing hope [36] by seeing it as immutable, making it possible to consider the temporal patterning of patients' expectations [37] when we examine their experience in healthcare contexts. This theoretical framework encourages us to analyse how the emotional experiences of hope and expectation are intimately connected with the actor's cognitive and moral evaluation of their environment (specifically, the embryo), acquiring different tones-in this case, according to the state of worth conferred on the embryo. Hope and expectation oscillate, shaping how embryos are understood depending on different stages of the treatment (e.g., phase of in vitro development), on vicissitudes (e.g., in vitro or in utero loss of embryos), on circumstances (e.g., classifications of the embryo) and on temporality (e.g., number of treatment cycles) that guide beneficiaries' therapeutic trajectories. Adopting this framework thus enables us to analyze how, from the perspective of a sociology of hope and expectation, entities, thoughts and actions are continuously shaped throughout a patient's clinical path.

We have seen that the revision of the embryo's prior classification occurs with the evaluation of its morphokinetic quality, a positive pregnancy test, or its transfer to the uterus, all of which are ontological markers. However, another specific emotional experience is associated with situations of ambivalence or tension in the formats through which beneficiaries engage with the embryo. This is true for another interviewee who, reflecting on her therapeutic trajectory, recounts the uncertainty experienced in relation to the embryo's moral status. Attached to this uncertainty is an emotional state of anguish, which stems from the tension between the conventional order that guides the professionals (doctors' and embryologists') approach to embryos in the lab and the meaning she, herself, produces around them, which is connected to a different grammar:

Aurora: "When she [the doctor] told me 'Okay, we have four, four blastocysts, and we'll have to freeze them, because there was overstimulation' ... At that moment I had questions [ ... ] and what I asked her was: 'Do the embryos feel anything when they are frozen? Do they feel anything when they are thawed?' And her response was that they didn't ... My motherly heart said something a little different $[\ldots]$. And, by the way, this question still remains with me, because I still have three frozen blastocysts ... [ . . ] When I advanced to this treatment, I'll admit, again, that I wasn't ready to deal with that sort of question, I thought it would be something very rational ... That it would be ... A process where those questions would not be relevant because they're microscopic things that you can't see ... However, it was difficult for me for that reason [ . . ] , although she'd tell me that the embryos didn't feel ... I still, I still feel some anguish [ ... ] I think that: 'If ... If I loved this embryo that I transferred, and the others ... If 
I've loved them since ... since I knew my eggs had been fertilized, this is worth something ... This has to mean something."'

Notwithstanding her reference to her "motherly heart" - which seemingly indicates a domestic grammar, with family relations and personal connection [38] used as a form of argument-the interviewee's discourse predominantly evokes an emotional experience marked by an intense affective investment of love-which comes under the framework of familiar engagement-in her relationship with the embryo. The word "heart" may, therefore, indicate an argument based not so much on a status (mother) associated with a family group, which would connect her to the lab-grown embryo under the conventional domestic order, but on an intimate involvement, one that is not accessible to actors that do not share the same experience of emotional investment [27].

This grammar is mobilized in opposition to the discourse of medical practitioners, who are embedded in an industrial grammar that understands the embryo as biological material, subject to a set of technical and scientific devices. Through a familiar form of engagement, the interviewee expresses a feeling of "anguish" about the procedures carried out on the embryo when understood through the industrial grammar (in particular, the laboratory procedures related to the freezing process).

The interviewee herself indicates this mismatch in cognitive and evaluative formats between beneficiary and professionals. She mentions her expectation, at the beginning of treatment, that her engagement format would converge with the environment occupied by beings from the industrial world, with repercussions for the related emotional experience ("I thought it would be something very rational")—-something that would be enabled by her non-visualization of the embryo ("microscopic things that you can't see") [7]. This rationality and distancing-which constitute an emotional framework that allows action to be mediated by the resources of technical objects and methods and oriented towards efficiency [29] in the execution of procedures (with procedural success or failure being the focus of the emotional experience) — contrasts with the emotional ambiance that characterises the beneficiary's relationship with the embryo, which is marked by the affective intensity associated with a familiar form of engagement.

Moreover, the interviewee's own description of the emotions, associated with losing the embryo after its transfer to her uterus, reinforces the latter regime of engagement. She mobilizes the category of "mourning" here-a category associated with singularisation that marks the use of a humanizing cognitive and moral format to understand the embryo, one that is far removed from understandings of a technical-scientific nature.

Aurora: "And when I saw it, to me it was very important to have the image of my embryo, especially for the mourning I'm going through with the miscarriage I had ... It was very important that I had an image, to me it was important, and it is important. I keep the image of my embryo near me ... [ . . ] It's here on my computer... And I like having this image here while I'm in the process of mourning..."

While the grammars used by beneficiaries mentioned so far all integrate the embryo into the parental project (whether as an instrument, cluster of cells, genetic inheritance, offspring, potential child, or child), the next excerpt provides an example of the embryo being reclassified in a way that dissociates it from this project- the project that gave rise to its creation. The interviewee describes how the cryopreserved embryos' shift into the category of surplus prompts them to reconfigure their evaluation as potential children under a connectionist grammar. Now that they are surplus, they are given the moral status of gift, and the beneficiary's emotional experience is subsequently recomposed:

Dalila: "I remember I wrote 'Today I have eleven children ... But tomorrow I don't know how many they'll be.' But it's like ... The expectations we had were so low that this didn't ... Except for the part about the twins, which was very real ... Of the confirmation of a positive ... [ ... ] The others didn't ... It was more like something ... a desire, but not a reality, you know? [ ... ] We'd always 
authorized them to be studied, and, actually, after it ended [ ... ] [husband's name] said 'No, we won't try again, and it's all going to be studied', and we signed documents ... That all of the embryos that weren't used ... as a life, for us, will be studied to help other people ..."

On the one hand, during the period of in vitro evolution, the interviewee describes the emotional state of "expectation"-associated with connectionist grammar-as connecting the couple to the lab-grown embryos. As she then reports, however, this expectation varied throughout the therapeutic trajectory. It was still "low" in the in vitro stage, given the high chance of failure, and the emotional connection with them as potential children remained restrained. It is the "confirmation of a positive" through a pregnancy test that reinforces the state of worth in this connectionist order, simultaneously intensifying the emotional connection with the embryos based on this same expectation. With the ontological marker of the pregnancy test, the embryo ceases to be only a "desire" to become closer to a "reality", and the status of potential or future child is reinforced.

On the other hand, as the interviewee reports, the pregnancy's realization at a later moment in the therapeutic trajectory, and the consequent closure of the parental project, prompts a reconfiguration of the embryos' status. The expectation and hope attached to them gives way to the desire to "help other people" —an emotional experience associated with the civic grammar. In this particular case, this solidarity-or sense of civic responsibility [3] - materializes in the form of the remaining embryos' donation for scientific research.

\section{Discussion}

ART beneficiaries' decision-making processes throughout their therapeutic trajectory are shaped by the interaction between cognition, moral evaluation, and emotion [39]. On the cognitive level, patients must decide and act within an environment composed of information about their prospects of success, the efficacy of technical procedures, and statistical data on health risks (e.g., genetic evaluation of the embryo), amid a context of uncertainty about the pregnancy's realization. These deliberative processes, in turn, incorporate moral judgments, which allow a moral status to be conferred on the lab-grown embryos. Additionally, different emotional responses, both positive and negative (pain, anguish, suffering, joy, etc.), arise in connection with different moments in the therapeutic trajectory [39].

Although many research projects have been conducted on the emotional experiences associated with an infertility diagnosis and the ART trajectory, their conceptual frameworks do not encourage us to look in detail at the plasticity of emotional states, or at how these states relate to oscillations in the embryo's ontological status [40].

Indeed, these studies tend to focus, mostly, on the evolution of beneficiaries' emotional states through categories such as depression, anxiety, or frustration-which are associated with treatments' success or failure-and deploy standardized instruments and questionnaires for clinical observations [24,41]. They include longitudinal studies that analyse how women and couples' emotions change both during and after treatment [42]. Other research is comparative, examining women and couples who experience success versus those that experience failure in achieving pregnancy, as well as the different emotional experiences and coping strategies of male and female members of heterosexual couples [18,22,43]. The decisions and occurrences, involving embryos at different stages of the therapeutic trajectory, are shown to be processes with a heavy emotional load [17,35], one whose effects go beyond the emotional experience strictly associated with infertility and moments of failure in accomplishing the parental project.

Other research suggests that the moral status conferred on the surplus embryos carries little weight in beneficiaries' decision-making processes, or point to a low level of plasticity in ontological constructs: instrumentalising views are thought to predominate, with embryos seen as resources mobilized for reproductive treatment [21,44,45]. Still, other research is based on a duality between emotion and evaluation [6], in which the emotional experience related to decision-making about an embryo (e.g., disquiet/discomfort about 
the prospect of donating embryos relegated to the status of surplus) overlaps with the decisions made (e.g., destruction), without necessarily being accompanied by a resolution at an evaluative level, that is, a definition or reconfiguration of the moral status attributed to the embryo.

By adopting a perspective guided by a sociology of engagements-one that integrates the cognitive, evaluative, and emotional dimensions present in the course of the therapeutic trajectory and related decision-making processes-this article proposes a more detailed analysis of the complexity of such emotional states. This analysis takes into account these states' multiple manifestations, how they oscillate at different moments in the therapeutic trajectory, and their articulation with the cognitive and moral frameworks that guide beneficiaries. This articulation is important because emotional states have an impact on decision-making processes [17]: emotional experiences not only play a part in, but are likely to lead to, the embryo's cognitive and moral re-evaluation (with consequences for deliberations about its fate), with the new status conferred on it leading to emotional appeasement $[33,34]$.

When inserted into the context of ART, the parental project moves away from the intimate, proximal, sphere of the couple [19]; as beneficiaries, they are inserted into a functionally prepared environment, one populated by devices of the industrial world [25] within a framework of technoscientific biomedicine [2]. However, immersion in this context does not necessarily entail the beneficiaries' adhesion exclusively to the cognitive and moral format guided by this composition of regimes of engagement, particularly when it comes to how they conceive of the embryo. Indeed, their actions may be guided by combinations of different regimes of engagement, which are accompanied, in turn, by correlated emotional tonalities.

Given this plurality of beneficiaries' regimes of engagement, the embryo may be understood using various different categories: child, promise/potential, genetic inheritance, offspring, and cluster of cells/biological material. These conceptualizations-which stem from different publicly-available grammars [27] — in turn entail specific emotional experiences that are connected to them.

Therefore, it is particularly in the moments when embryos are reclassified that the emotional states, associated with specific cognitive and moral formats, are most evident. This is because the change in the embryo's status, and the process of re-evaluation on which it is based, increases the emotional ambiance associated with the grammar (or composition of grammars) that supports this reclassification. At the end of a moment of test-of the situation's (re)definition according to a regime of engagement (in this case, of questioning how the embryos are classified) - there is emotional appeasement. During these moments of test, however, emotional investments are intensified, shaping the construction of judgments and serving as catalysts for re-evaluation [33]. In particular, the emotions associated with the evaluation of a situation, based on a given regime of engagement, trigger this same exercise of reclassification [29].

These emotional investments, experienced by beneficiaries, are highlighted at specific stages of the therapeutic trajectory-for instance, when the embryo is displaced either in time (e.g., embryonic development stage or the woman getting pregnant) or in space (e.g., transfer into the uterus), or at other moments, such as technical-scientific evaluations (e.g., measurement of the embryo's quality/potential, translated into a probability of achieving pregnancy, or a positive pregnancy test) or biomedical visualization (which make use of technical devices, such as an ultrasound or photos of the embryos).

It is, therefore, the interaction between time, space, clinical judgments, and sensory engagement that determines the different situations in which couples/beneficiaries juggle between different grammars [31] when producing meanings around the embryos. This multi-layered grammatical structure accompanies beneficiaries' subjective progression throughout the clinical path-from the beginning until the end of the parental projectand can change during this path's different moments of success and failure, its setbacks, deadlocks, and restarts. Grammars support the changing meanings (and emotions) around 
the embryo that influence decision-making in the present, giving new sense to what has occurred in the past and making sense of future possibilities (e.g., when deciding the fate of surplus embryos).

The different stages and contingencies of the therapeutic trajectory are thus liable to trigger reconfigurations in the meanings attributed to embryos, and are accompanied by emotional ambiances associated with the normative format(s) through which the embryo is re-evaluated. Concretely, we can identify three types of key moments of emotional oscillation among the beneficiaries that are associated with changing moral judgments about the embryo:

a. Moments of ambivalence related to the embryo's status (e.g., the execution of clinical procedures on the embryo-such as preimplantation genetic testing-for measuring its quality and development potential, according to an industrial logic; this is in tension with a caring and singularizing connection to the embryo associated with a familiar form of engagement, which generates the emotional experiences of anguish or disquiet);

b. Moments where the embryo's state of worth is revised within the same regime of engagement (e.g., where the embryo's status as hope is strengthened within a connectionist grammar after the evaluation of the embryo's good quality or a positive pregnancy test that reinforces the possibility of achieving pregnancy);

c. Moments where the regime of engagement is revised, leading to a transition between orders of worth or regimes of engagement (e.g., the embryo's transition from being seen as a cluster of cells - in line with an instrumental conception, associated with an industrial grammar combined with an engagement in a plan-to being seen as progeny/offspring within the domestic grammar, leading to the emotional experience of affection or tenderness).

Now, these evaluative and emotional changes in the beneficiaries' relationship with the embryo are more pronounced than those of the professionals involved in the therapeutic plan-in particular, doctors and embryologists. Consequently, tensions and inhospitable situations [46] may occur during their interactions. These take the form of dissonances between users and professionals in how they understand the embryo, as well as situations where clinics are unable to accommodate patients' evaluative formats, which diverge from the industrial grammar that predominates in the functioning of ART clinics/units and in the action logics of their staff.

By mapping these patterns of oscillation of emotional ambiances and ontological constructs - which we have tried to do in detail-we have sought to produce a tool for reflecting about the procedures and practices in ART clinics/units. Besides beneficiaries' decision-making autonomy being a normative goal (because it safeguards users' agency without challenging professionals' technical-scientific authority), the beneficiaries we interviewed make critical judgments about their therapeutic trajectory using the grammar of hospitality [46].

Participation in an institution/organization implies sharing common objectives and conforming to collective normative frameworks that regulate all activity carried out within it. This is supported by the participants' investment in forms, and particularly, standardized norms that guide actions and perspectives [26]. The grammar of hospitality is one such normative framework that can be used to judge how institutions/organizations function. It is concerned with evaluating these institutions/organizations' capacity to accommodate users' specificities and vulnerabilities. Within the grammar of hospitality, the goal is to facilitate participants' integration in the institution/organization by accommodating singularities/differences and thus, ensuring the ability for each to participate in it.

Questions of hospitality arise around ART units/clinics' ability to accommodate different understandings and modes of connecting with embryos, which can differ from those recognized by the standardized norms that regulate the functioning of ART units/clinics as organizations [13]; their ability to better address couples' vulnerabilities, such as the 
range of emotions that beneficiaries feel towards the embryos, can compromise/affect their decision-making capacity due to their potential emotional charge [17].

The grammar of hospitality is, therefore, mobilized by beneficiaries as a moral foundation for critiquing how the lab-grown embryos are understood and acted upon. Thus, the perspectives conveyed by the interviewees frequently seek greater accommodation by these ART units of ways of conceptualizing the embryo that are dissociated from the biomedical discourse- and the consequent recognition of the fluctuations and plasticity in beneficiaries' emotional states, in relation to the embryo, that are not limited to the stress, anxiety, or suffering associated with the non-achievement of the pregnancy (i.e., engagement in a plan). However, the plasticity of institutions/organizations is constrained by the set of standards that regulate their functioning [26]. If these institutions/organizations are to become more accommodating, then these standards that guide professionals' conduct (that of medical doctors, embryologists, nurses, etc.) need to be improved, so they can better incorporate this plurality of meanings and emotional states around the embryos that beneficiaries can display.

More detailed knowledge about the plurality of meanings likely to be attributed to the embryo — and about oscillations in the associated emotional experiences-also highlights the importance of supplying information to beneficiaries through procedures that go beyond the process of gaining beneficiaries' formal authorization. Concretely, when obtaining informed consent about what happens to the embryo, professionals should follow standard procedures that encourage more continuous follow-up, starting from the moment when beneficiaries decide to move forward with IVF/ICSI. It should be made easier for beneficiaries to communicate the dilemmas that arise for them, as well as the emotional implications of the decision-making processes involving the lab-grown embryos.

Author Contributions: Writing—original draft preparation, L.G.; writing—review and editing, L.G., C.D.; project administration, C.D. All authors have read and agreed to the published version of the manuscript.

Funding: This research was funded by the FCT-Foundation for Science and Technology, I.P., grant number PTDC/SOC-SOC/29764/2017. In addition, this work was funded by national funds through FCT—Foundation for Science and Technology, I.P., within the scope of the project «UIDB/04647 / 2020» of CICS.NOVA-Interdisciplinary Centre of Social Sciences of Universidade Nova de Lisboa.

Institutional Review Board Statement: The study was conducted according to the guidelines of the Declaration of Helsinki, and approved by the Ethics Committee of the Universidade NOVA de Lisboa (25 September 2019).

Informed Consent Statement: Informed consent was obtained from all subjects involved in the study.

Data Availability Statement: The data presented in this study are available on request from the project administrator.

Acknowledgments: The authors acknowledge the contribution of the professional translator Guilherme Lucas Rodrigues Monteiro and of the professional proof-reader Josh Booth.

Conflicts of Interest: The authors declare no conflict of interest. The funders had no role in the design of the study, in the collection, analyses, or interpretation of data, in the writing of the manuscript, or in the decision to publish the results.

\section{References}

1. Dow, K. 'Now She's Just an Ordinary Baby': The Birth of IVF in the British Press. Sociology 2019, 53, 314-329. [CrossRef]

2. Clarke, A.E.; Shim, J.K.; Mamo, L.; Fosket, J.R.; Fisherman, J.R. Biomedicalization: Technoscientific Transformations of Health, Illness and U.S. Biomedicine. Am. Sociol. Rev. 2003, 68, 161-194. [CrossRef]

3. Svendsen, M.N. Between reproductive and regenerative medicine: Practicing embryo donation and civil responsibility in Denmark. Body Soc. 2007, 13, 21-45. [CrossRef]

4. De Lacey, S. Death in the clinic: Women's perceptions and experiences of discarding supernumerary IVF embryos. Sociol. Health Illn. 2017, 39, 397-411. [CrossRef] 
5. Haimes, E.; Porz, R.; Scully, J.L.; Rehmann-Sutter, C. "So, what is an embryo?" A comparative study of the views of those asked to donate embryos for hESC research in the UK and Switzerland. New Genet. Soc. 2008, 27, 113-126. [CrossRef]

6. Provoost, V.; Pennings, G.; De Sutter, P.; Gerris, J.; Van de Velde, A.; De Lissnyder, E.; Dhont, M. Infertility patients' beliefs about their embryos and their disposition preferences. Hum. Reprod. 2009, 24, 896-905. [CrossRef] [PubMed]

7. Boltanski, L. The Foetal Condition. A Sociology of Engendering and Abortion; Polity Press: Cambridge, UK, 2013.

8. Bruno, C.; Dudkiewicz-Sibony, C.; Berthaut, I.; Weil, E.; Brunet, L.; Fortier, C.; Pfeffer, J.; Ravel, C.; Fauque, P.; Mathieu, E.; et al. Survey of 243 ART patients having made a final disposition decision about their surplus cryopreserved embryos: The crucial role of symbolic embryo representation. Hum. Reprod. 2016, 31, 1508-1514. [CrossRef]

9. Cussins, C.M. Ontological Choreography: Agency for women patients in an infertility clinic. In Differences in Medicine: Unraveling Practices, Techniques, and Bodies, 1st ed.; Berg, M., Mol, A., Eds.; Duke University Press: Durham, UK; London, UK, 1998; pp. 166-201.

10. Thompson, C. Making Parents: The Ontological Choreography of Human Reproductive Technologies; MIT Press: Cambridge, UK; London, UK, 2005.

11. De Lacey, S. Decisions for the fate of frozen embryos: Fresh insights into patients' thinking and their rationales for donating or discarding embryos. Hum. Reprod. 2007, 22, 1751-1758. [CrossRef] [PubMed]

12. Rosemann, A.; Luo, H. Attitudes Towards the Donation of Human Embryos for Stem Cell Research Among Chinese IVF Patients and Students. J. Bioeth. Inq. 2018, 15, 441-457. [CrossRef]

13. Silva, S.; Machado, H. Legal, medical and lay understanding of embryos in Portugal: Alignment with biology? Interface Commun. Health Educ. 2009, 13, 31-43. [CrossRef]

14. Delaunay, C.; Santos, M.J.; Gouveia, L. In vitro metaphors: ART beneficiaries' meaning-making on human embryos in the context of IFV in Portugal. Reprod. Biomed. Soc. Online 2021, 13, 62-74. [CrossRef]

15. Samorinha, C.; Pereira, M.; Machado, H.; Figueiredo, B.; Silva, S. Factors associated with the donation and non-donation of embryos for research: A systematic review. Hum. Reprod. Updat. 2014, 20, 641-655. [CrossRef] [PubMed]

16. Samorinha, C.; Severo, M.; Machado, H.; Figueiredo, B.; De Freitas, C.; Silva, S. Couple's willingness to donate embryos for research: A longitudinal study. Acta Obstet. Gynecol. Scand. 2016, 95, 912-919. [CrossRef] [PubMed]

17. Provoost, V.; Pennings, G.; De Sutter, P.; Dhont, M. "Something of the two of us". The emotionally loaded embryo disposition decision making of patients who view their embryo as a symbol of their relationship. J. Psychosom. Obstet. Gynecol. 2012, 33, 45-52. [CrossRef]

18. Hsu, Y.-L.; Kuo, B.-J. Evaluations of Emotional Reactions and Coping Behaviors as Well as Correlated Factors for Infertile Couples Receiving Assisted Reproductive Technologies. J. Nurs. Res. 2002, 10, 291-302. [CrossRef]

19. Delaunay, C. L'insupportable et l'incertain. Proximité et détachement dans l'assistance médicale à la procréation avec tiers donneur Anthropol. Santé. 2017, 15. Available online: http:/ / anthropologiesante.revues.org/2738 (accessed on 29 December 2021).

20. De Lacey, S. Parent identity and 'virtual' children: Why patients discard rather than donate unused embryos. Hum. Reprod. 2005, 20, 1661-1669. [CrossRef] [PubMed]

21. Provoost, V.; Pennings, G.; De Sutter, P.; Gerris, J.; Van De Velde, A.; Dhont, M. Patients' conceptualization of cryopreserved embryos used in their fertility treatment. Hum. Reprod. 2010, 25, 705-713. [CrossRef]

22. Merari, D.; Chetrit, A.; Modan, B. Emotional Reactions and Attitudes Prior to In Vitro Fertilization: An Inter-Spouse Study. Psychol. Heal. 2002, 17, 629-640. [CrossRef]

23. Hjelmstedt, A.; Widström, A.-M.; Wramsby, H.M.; Collins, A. Patterns of emotional responses to pregnancy, experience of pregnancy and attitudes to parenthood among IVF couples: A longitudinal study. J. Psychosom. Obstet. Gynecol. 2003, 24, 153-162. [CrossRef]

24. Verhaak, C.M.; Smeenk, J.M.J.; Evers, A.W.M.; Kremer, J.A.M.; Kraaimaat, F.W.; Braat, D.D.M. Women's emotional adjustment to IVF: A systematic review of 25 years of research. Hum. Reprod. Updat. 2007, 13, 27-36. [CrossRef]

25. Boltanski, L.; Thévenot, L. On Justification. Economies of Worth; Princeton University Press: Princeton, NJ, USA, 2006.

26. Thévenot, L. L'action au Pluriel. Sociologie des Régimes D'engagement; Éditions La Découverte: Paris, France, 2006.

27. Thévenot, L. What engages? The sociology of justifications, conventions, and engagements, meeting norms. La Rev. Des Droits De L'homme 2019, 16. Available online: http:/ /journals.openedition.org/revdh/7114 (accessed on 29 December 2021). [CrossRef]

28. Thévenot, L. The plurality of cognitive formats and engagements: Moving between the familiar and the public. Eur. J. Soc. Theory 2007, 10, 413-427. [CrossRef]

29. Livet, P.; Thévenot, L. Modes d'action collective et construction éthique. Les émotions dans l'évaluation. In Les Limites de La Rationalité, 1st ed.; Dupuy, J.-P., Livet, P., Eds.; La Découverte: Paris, France, 1993; Volume 1, pp. $412-439$.

30. Kaufmann, L.; Quéré, L. (Eds.) Les émotions Collectives: En Quête d'un «Objet» Impossible; Éditions de l'EHESS: Paris, France, 2020.

31. Gajdoš, A.; Rapošová, I. Juggling grammars, translating common-place: Justifying an anti-liberal referendum to a liberal public. Eur. J. Cult. Polit. Sociol. 2018, 5, 165-193. [CrossRef]

32. Pattaroni, L. Le care est-il institutionnalisable? Quand la «politique du care» émousse son éthique. In Le Souci des Autres. Éthique et Politique du Care, 2nd ed.; Paperman, P., Laugier, S., Eds.; Éditions de l'EHESS: Paris, France, 2011; pp. 209-233. [CrossRef]

33. Thévenot, L. Émotions et Évaluations dans les coordinations publiques. In La Couleur des Pensées. Émotions, Sentiments, Intentions, 1st ed.; Paperman, P., Ogien, R., Eds.; Éditions de l’EHESS: Paris, France, 1995; pp. 145-174. 
34. Genard, J. Une sociologie des émotions «modo aesthetico»? In Les émotions Collectives: En Quête D'un «Objet» Impossible, 1st ed.; Kaufmann, L., Quéré, L., Eds.; Éditions de l'EHESS: Paris, France, 2020; pp. 169-203. [CrossRef]

35. Toscano, S.E.; Montgomery, R.M. The lived experience of women pregnant (including preconception) post in vitro fertilization through the lens of virtual communities. Health Care Women Int. 2009, 30, 1014-1036. [CrossRef] [PubMed]

36. Peterson, A.; Wilkinson, I. Editorial introduction: The sociology of hope in contexts of health, medicine, and healthcare. Heal. Interdiscip. J. Soc. Study Heal. Illn. Med. 2015, 19, 113-118. [CrossRef] [PubMed]

37. Borup, M.; Brown, N.; Konrad, K.; van Lente, H. The sociology of expectations in science and technology. Technol. Anal. Strat. Manag. 2006, 18, 285-298. [CrossRef]

38. Lebedev, A.C. Lebedev, A.C. Le cœur politique des mères. In Analyse du Mouvement des Mères de Soldats en Russie; Éditions de l'EHESS: Paris, France, 2013.

39. Hershberger, P.E.; Pierce, P.F. Conceptualizing couples' decision making in PGD: Emerging cognitive, emotional, and moral dimensions. Patient Educ. Couns. 2010, 81, 53-62. [CrossRef] [PubMed]

40. Adrian, S.W. Psychological IVF: Conceptualizing emotional choreography in a fertility clinic. Distinktion Scand. J. Soc. Theory 2015, 16, 302-317. [CrossRef]

41. Mahlstedt, P.P.; MacDuff, S.; Bernstein, J. Emotional factors and the in vitro fertilization and embryo transfer process. J. Assist. Reprod. Genet. 1987, 4, 232-236. [CrossRef] [PubMed]

42. Slade, P.; Emery, J.; Lieberman, B.A. A prospective, longitudinal study of emotions and relationships in in-vitro fertilization treatment. Hum. Reprod. 1997, 12, 183-190. [CrossRef]

43. Shaw, P.; Johnston, M.; Shaw, R. Counselling needs, emotional and relationship problems in couples awaiting IVF. J. Psychosom. Obstet. Gynecol. 1988, 9, 171-180. [CrossRef]

44. Svanberg, A.; Boivin, J.; Bergh, T. Factors influencing the decision to use or discard cryopreserved embryos. Acta Obstet. Gynecol. Scand. 2001, 80, 849-855. [CrossRef] [PubMed]

45. Holter, H.; Bergh, C.; Gejervall, A.-L. Lost and lonely: A qualitative study of women's experiences of no embryo transfer owing to non-fertilization or poor embryo quality. Hum. Reprod. Op. 2021, 2021, hoaa062. [CrossRef] [PubMed]

46. Stavo-Debauge, J. Qu'est-ce que L'hospitalité. Recevoir L'étranger à la Communauté; Liber: Montréal, QC, Canada, 2017. 